\title{
FUNDAMENTOS TEÓRICOS E EMPÍRICOS DE APREÇAMENTO DE ATIVOS
}

\author{
Richard Saito \\ Professor da FGV-EAESP \\ E-mail: richard.saito@fgv.br \\ Rodrigo de Losso da Silveira Bueno \\ Professor da FGV-EAESP \\ E-mail: rodrigo.bueno@fgv.br
}

\section{INTRODUÇÃO}

Os dois textos que inauguram a série "RAE-Clássicos" de Finanças fundamentam a teoria moderna de apreçamento de ativos. Enquanto o trabalho de Cox, Ingersoll e Ross (1985b) é teórico e desenvolvido em tempo contínuo, o de Fama e French (2004) é empírico e desenvolvido em tempo discreto. Fama e French (2004) fazem um relato histórico até os dias de hoje do modelo CAPM (Capital Asset Pricing Model), idealizado por Sharpe (1964), Lintner (1965) e Mossin (1966). Já Cox, Ingersoll e Ross (1985b), doravante CIR, desenvolvem um modelo de apreçamento de opções de juros.

Embora à primeira vista CAPM e CIR pareçam modelos completamente diferentes, ambos são baseados no modelo de equilíbrio geral dinâmico estocástico de Lucas (1978), que unificou as teorias de apreçamento no chamado CAPM baseado em Consumo (CCAPM). Assim, é possível mostrar que o CAPM é um caso especial do CCAPM, quando o fator estocástico de desconto é linear nos retornos da carteira de mercado. O modelo CIR, por sua vez, sustenta-se numa evolução de Lucas (1978) em que a produção é endógena e há mudanças tecnológicas aleatórias (veja Cox, Ingersoll e Ross, 1985a).

As seções seguintes detalham a importância de cada um desses textos na área de finanças e procuram apontar veias inexploradas de pesquisa no Brasil.

\section{O MODELO CAPM}

A teoria "moderna" de Finanças fundamenta-se no trabalho seminal de Markowitz (1952), pelo qual existe uma fronteira eficiente de ativos. Ainda que isso tivesse forte apelo intuitivo, era preciso mostrar que a alocação dos agentes seria feita em algum ponto dessa fronteira. Sob certas hipóteses, Sharpe (1964) foi o primeiro a mostrar esse fato, quando desenvolveu o modelo CAPM, a seguir:

$$
\begin{aligned}
& E\left(R_{j, t+1}\right)=R_{F}+\beta_{j} \lambda, \\
& \beta_{j} \equiv \frac{\operatorname{cov}\left(R_{m, t+1}, R_{j, t+1}\right)}{\operatorname{var}\left(R_{m, t+1}\right)} ; \lambda \equiv E\left(R_{m, t+1}\right)-R_{F}
\end{aligned}
$$

em que:

E é o operador esperança;

$R_{j, t}$ é o retorno bruto do ativo $j$ no período $t$;

$R_{m, t}$ é o retorno da carteira de mercado $(m)$, sendo esta constituída de todos os ativos da economia no período $t$;

$R_{\mathrm{F}}$ é o retorno do ativo livre de risco; $\operatorname{cov}($.$) é o operador covariância;$

$\operatorname{var}($.$) é o operador variância;$

$\lambda \equiv E\left(R_{m, t+1}\right)-R_{F}$ é chamado de prêmio de mercado. 
Embora simples, esse modelo não é muito fácil de estimar. Mas é por causa dessa aparente simplicidade de estimação que o CAPM tem sido largamente utilizado por profissionais de mercado e na academia. O mercado utiliza o modelo no cálculo do custo de capital e na avaliação de desempenho de fundos de investimento, principalmente. Na academia, o CAPM se reproduz nos livros-textos de Finanças tanto na graduação como em especializações e pós-graduação (veja Sharpe et al., 1999; Haugen, 2001; e Bodie, Kane e Marcus, 2005, para citar alguns exemplos).

Claro que o grande interesse pelo modelo CAPM e sua larga utilização tem a ver não apenas com sua simplicidade de interpretação, mas também com sua fácil implementação e, principalmente, porque gerou hipóteses testáveis empiricamente.

O texto de Fama e French (2004), à semelhança do de Jensen (1972), é um apanhado crítico da literatura empírica do CAPM. Busca apontar o desenvolvimento dos testes empíricos do modelo ao longo dos anos e os desenvolvimentos recentes, com ênfase no modelo "CAPM de três fatores" de Fama e French (1993).

Sob essa análise crítica, o leitor é levado a reconsiderar em profundidade suas convicções a respeito do CAPM, em virtude da ênfase com que os autores rejeitam empiricamente o modelo e ressaltam as vantagens do seu modelo de três fatores.

É preciso enfatizar que o modelo CAPM de três fatores surgiu a partir de uma agenda de pesquisa empírica em finanças que se manteve por longos anos e culminou com o artigo de 1993. Assim, Fama e French (2004) evidenciam que seu modelo de três fatores é capaz de reproduzir os dados observados. A justificativa de sucesso de seu modelo deve-se a argumentos muito convincentes e bem fundamentados, bem como ao fato de manter a simplicidade de construção do modelo, porém não têm embasamento teórico a partir de princípios fundamentais da teoria do consumidor.

O texto se inicia traçando os fundamentos teóricos do CAPM e estabelecendo suas hipóteses testáveis de uma forma metodológica bastante clara. O passo seguinte é ligar essas hipóteses aos métodos empíricos para testálas de forma surpreendentemente simples, que revela a maestria desses autores.

No segundo terço do artigo, Fama e French descrevem os primeiros testes do CAPM. Ali explicam aos leitores mais jovens por que se usam carteiras de ativos em vez de ativos individuais para estimar os betas. Esse ponto é importante, porque no Brasil talvez isso seja desnecessário, considerando o reduzido número de ações transacionadas no mercado diariamente, sem interrupção.
Fama e French (2004) avançam mostrando por que o CAPM é rejeitado empiricamente e mostram maneiras de se verificar isso por meio de gráficos. Uma vez caracterizada a rejeição do CAPM, eles descrevem o modelo de três fatores e sugerem uma fundamentação teórica, via ICAPM ou APT. Os autores concluem seu texto dizendo que o CAPM, embora seja assunto de livros-texto tradicionais e, por isso, largamente ensinado na academia, encerra problemas que o invalidam completamente.

Nada obstante essa conclusão, é preciso qualificar melhor a discussão dos pontos de vista teórico e empírico. Em primeiro lugar, é difícil definir o ativo livre de risco e a carteira de mercado a serem utilizados no modelo, particularmente quando se pensa no Brasil. Assim, a literatura especializada avança por essas vias, e há quem considere a solução de Fama e French (1993) inválida. $\mathrm{Na}$ verdade, a discussão não está concluída, e o artigo serve como ponto de partida para novas idéias, dada sua clareza de hipóteses e procedimentos para testes empíricos do CAPM. Isso vale inclusive para o Brasil, onde poucas pessoas testam, de fato, o modelo como se deve, porque evitam usar o método de Fama e McBeth (1973) ou o GMM de Hansen e Singleton (1983) para estimar o prêmio de mercado.

Como conseqüência dessas descobertas e do desenvolvimento de modelos de apreçamento dinâmicos estocásticos, os testes dos modelos modernos têm se baseado na metodologia empírica criada por Fama e French, sintetizada em seu artigo de 2004, como exemplificam Lettau e Ludvigson (2001) e Yogo (2006), entre outros autores.

No Brasil, vários autores buscam estimar o modelo CAPM. Entretanto, poucos usam a metodologia de Fama e French (2004), e, por isso, trata-se de uma agenda de pesquisa que ainda precisa ser mais bem explorada. Uma das razões dessa dificuldade é a escassez de dados confiáveis, mesmo considerando empresas transacionadas em bolsa, associados ao largo período megainflacionário vivido no Brasil, onde prevaleciam aplicações de renda fixa. Uma segunda razão é a dificuldade de entender as sutilezas técnicas de estimação do modelo, ainda que o GMM tenha simplificado consideravelmente o trabalho. Os trabalhos nessa direção estão reunidos na primeira parte de Bonomo (2002), com resultados ainda não propriamente consolidados.

\section{O MODELO DE COX, INGERSOLL E ROSS (CIR)}

Cox, Ingersoll e Ross (1985a) relaxaram algumas hipóteses de Lucas (1978) e desenvolveram um modelo de 
equilíbrio geral bastante elegante para o apreçamento de ativos em tempo contínuo.

Com base nesse modelo, os mesmos autores construíram uma teoria para explicar a estrutura a termo da taxa de juros em um artigo paralelo, desenvolvendo o modelo CIR. Trata-se de um modelo bastante geral por englobar características de outras teorias que explicam a estrutura a termo de juros por meio das hipóteses de expectativas, de preferência por liquidez ou da segmentação de mercado.

Inúmeros trabalhos empíricos surgiram a partir de então, usando esses modelos e testando seu poder preditivo, sua capacidade de explicação de fatos estilizados e evolução de preços de opções com maior ou menor sucesso, dependendo da série e do período escolhido.

Inicialmente o artigo apresenta as hipóteses do modelo e os resultados de Cox, Ingersoll e Ross (1985a) a serem usados na derivação do modelo da estrutura a termo. Por ser um modelo estocástico desenvolvido em tempo contínuo, é preciso adquirir a intuição dos resultados. Isso é feito por meio de um exemplo em que se admite que haja um único fator a explicar a estrutura a termo. Trata-se de uma seção importante, porque o exemplo permite visualizar os principais resultados gerais de forma bastante simples.

A quarta seção é bem curta, mas é onde se encontra a fórmula de apreçamento de opções de juros e uma das razões mais importantes do sucesso do artigo, essencialmente porque o modelo não é muito mais difícil de implementar do que o modelo de Black e Scholes (1973). A seção seguinte é interessante porque os autores comparam sua metodologia de apreçamento com as que usam argumentos de não arbitragem, e, naturalmente, concluem que seu método é mais vantajoso. O artigo termina determinando a estrutura a termo por meio de múltiplos fatores e incorporando a inflação, o que constituiu um grande avanço técnico para a época.

Todos os modelos de apreçamento de opções de juros que se desenvolveram depois ou foram uma aplicação explícita das fórmulas de Cox, Ingersoll e Ross (1985b) ou foram variantes, com o objetivo de maior precisão. De fato, o modelo CIR, junto com o de Vasicek (1977), forma os fundamentos do apreçamento moderno de opções de juros. Esses autores inspiraram os modelos como os de Ho e Lee (1986), Hull e White (1990), e Heath, Jarrow e Morton (1992). Tais modelos são aperfeiçoamentos ou particularizações para casos em que se podem obter esclarecimentos mais profundos. Por exemplo, Hull e White (1990) estendem o CIR introduzindo volatilidade dependente do tempo, usando futuros de taxa de juros.

Trata-se de modelos desenvolvidos em tempo contínuo, cujos dados são observados em tempo discreto. A par do desafio intelectual de implementar esse modelo, logo surgiu a necessidade de estimar os parâmetros que o determinam para proceder à calibragem. Então, boa parte da literatura sobre estimação de modelos contínuos usa o exemplo do CIR como aplicação dos métodos desenvolvidos.

É importante reforçar a generalidade do modelo para explicar o formato da curva de juros. Com isso em mente, dado que o preço da opção de juros depende do formato dessa curva, e uma vez estabelecida a teoria que a fundamenta, a extensão natural é usar esse resultado para obter o preço da opção.

No Brasil, o modelo CIR é implementado em várias instituições financeiras; mas, na literatura nacional, são raros os artigos científicos que utilizam o CIR. A razão desse fato é que os pesquisadores locais preferem usar variantes mais modernas do modelo CIR. Entre os poucos autores que estudaram o modelo CIR e o aplicaram ao Brasil se destacam Vieira Neto (1999), Oliveira (2003), e Barbachan e Ornelas (2003). Em geral, os testes empíricos procuram mostrar que o modelo CIR produz melhores resultados que o modelo de Vasicek.

\section{COMENTÁRIOS FINAIS}

Este texto introduz dois importantes artigos a respeito da literatura em Finanças. Tais artigos têm uma mesma fundamentação teórica em Lucas (1978). Trata-se de textos com diferentes preocupações, abordando mesmo diferentes mercados de ativos: um de renda variável e outro de renda fixa.

Um ponto que sobressai é o fato de textos de objetivos tão distintos se apoiarem sobre o mesmo modelo teórico chamado de CAPM de consumo. Trata-se da unificação dos modelos de apreçamento, elegantemente promovida por Lucas (1978).

Esses textos sustentam inúmeros trabalhos teóricos e empíricos que vêm sendo desenvolvidos. A partir deles, a fronteira de Finanças se estendeu, e um leque de novas oportunidades surgiu. Importante, nesse desenvolvimento, é entender que se levantaram novas questões, para as quais ainda se buscam respostas. Por exemplo, o modelo CAPM de Sharpe (1964) está definitivamente superado? A resposta é difícil porque o modelo CAPM de três fatores de Fama e French é totalmente empíri- 
co, e não existe uma teoria consistente que o justifique plenamente.

A pesquisa em Finanças no Brasil ainda engatinha por várias razões. Entre elas, dados insuficientes em razão do largo período megainflacionário vivido no Brasil, e uma massa crítica acadêmica ainda tomando corpo. Como resultado, é baixo o número de trabalhos sobre apreçamento de ativos, o que também decorre, em parte, da formação técnica insuficiente de nossos pesquisadores locais.

Com a superação do período megainflationário, emergem alguns efeitos importantes de estímulo à pesquisa em Finanças. Em primeiro lugar, para ser estimado, o CAPM precisa da taxa de retorno do ativo livre de risco e da carteira de mercado. Ora, nunca houve títulos préfixados de prazo suficientemente longo que servissem como taxa de retorno livre de risco, à semelhança dos bonds de diferentes maturidades existentes nos Estados Unidos. Assim, usava-se o CDI com ativo livre de risco, embora fosse uma taxa ex-post. Recentemente, foram lançados títulos de 10 anos no mercado internacional, pré-fixados, nominados em reais. Esses títulos são candidatos naturais à taxa livre de risco do Brasil assim que houver decorrido tempo suficiente para o acúmulo de dados. A importância dessa nova estrutura econômica é evidente por ser agora possível calcular corretamente o prêmio de risco no Brasil, a partir de expectativas de retornos. Ou seja, mais do que nunca é possível rever os modelos empíricos de teste do CAPM, e incorporar as lições de Fama e French (2004).

Simultaneamente, o efeito da queda da taxa de juros traz novos desafios para os pesquisadores, que poderão usar mais e melhor os modelos que explicam a estrutura a termo da taxa de juros e apreçam ativos financeiros. Agora, os operadores de mercado deverão concentrar suas atividades na operação de derivativos de juros, onde deverão existir melhores oportunidades de negócio. É particularmente nessa área que o modelo CIR e seus derivados se aplicam. Haverá mais dados para os pesquisadores testarem modelos e compararem os resultados com a literatura internacional, quem sabe conseguindo responder por que as taxas de juros no Brasil são tão altas.

\section{REFERÊNCIAS}

BARBACHAN, J. S. F;; ORNELAS, J. R. H. Apreçamento de opções IDI usando o modelo CIR. Estudos Econômicos, v. 33, n. 2, p. 287-323, 2003.
BLACK, F.; SCHOLES, M. The pricing of options and corporate liabilities. The Journal of Political Economy, v. 81, n. 3, p. 637-654, 1973.

BODIE, Z.; KANE, A.; MARCUS, A. J. Investments. 6th ed. New York: McGraw-Hill, 2005.

BONOMO, M. Finanças aplicadas ao Brasil. Rio de Janeiro: FGV Editora, 2002

COX, J. C.; INGERSOLL, J. E.; ROSS, S. A. An intertemporal general equilibrium model of asset prices. Econometrica, v. 53, n. 2, p. 363-384, 1985 a.

COX, J. C.; INGERSOLL, J. E.; ROSS, S. A. A theory of the term structure of interest rates. Econometrica, v. 53, n. 2, p. 385-408, 1985 b.

FAMA, E. F; FRENCH, K. R. The capital asset pricing model: theory and evidence. Journal of Economic Perspectives, v. 18, n. 3, p. 25-46, 2004.

FAMA, E. F; FRENCH, K. R. Common risk factors in the returns of stock and bonds. Journal of Financial Economics, v. 33, n. 1, p. 3-56, 1993.

FAMA, E. F; MCBETH, J. D. Risk, return, and equilibrium: empirical tests. Journal of Political Economy, v. 81, n. 3, p. 607-636, 1973.

JENSEN, M. C. Capital markets: theory and evidence. Bell Journal of Economics and Management, v. 3, n. 2, p. 357-398, 1972.

HANSEN, L. P. Large sample properties of generalized method of moments estimators. Econometrica, v. 50, n. 4, p. 1029-1054, 1982.

HANSEN, L. P.; SINGLETON, K. J. Stochastic Consumption, Risk Aversion, and the Temporal Behavior of Asset Returns. Journal of Political Economy, v. 91, n. 2, p. 249-268, 1983.

HAUGEN, R. A. Modern Investment Theory. 5th. ed. Upper Saddle River: Prentice Hall, 2001.

HEATH, D.; JARROW, R.; MORTON, A. Bond pricing and the term structure of interest rates: a new methodology for contingent claims valuation. Econometrica, v. 60, n. 1, p. 77-105, 1992.

HO, T. S. Y.; LEE, S.-B. Term structure movements and pricing interest rate contingent claims. The Journal of Finance, v. 41, n. 5, p. 1011-1029, 1986

HULL, J.; WHITE, A. Pricing interest-rate derivatives securities. The Review of Financial Studies, v. 3, n. 4, p. 573-592, 1990.

LETTAU, M.; LUDVIGSON, S. Resurrecting the (C) CAPM: a cross-sectional test when risk premia are time-varying. Journal of Political Economy, v. 109, n. 6, p. 1238-1287, 2001. 
RICHARD SAITO - RODRIGO DE LOSSO DA SILVEIRA BUENO

LINTNER, J. The valuation of risk assets and the selection of risky investments in stock portfolios and capital budgets. Review of Economics and Statistics, v. 47, n. 1, p. 13-37, 1965.

LUCAS JR., R. E. Asset pricing in an exchange economy. Econometrica, v. 46, n. 6, p. 1429-45, 1978 .

MARKOWITZ, H. Portfolio selection. Journal of Finance, v. 7, n. 1, p. 77-99, 1952

MOSSIN, J. Equilibrium in capital asset market. Econometrica, v. 34, n. 4, p. $768-783,1966$

OLIVEIRA, A. A. S. Modelos de estrutura a termo de taxa de juros: um teste empírico. Rio de Janeiro, 2003. 34 p. Dissertação (Mestrado em Economia) - Escola de Pós-Graduação em Economia - EPGE, Fundação Getulio Vargas.
SHARPE, W. F. Capital asset prices: a theory of market equilibrium. Journal of Finance, v. 19, n. 3, p. 425-442, 1964.

SHARPE, W. F. ET AL. Investments. 3rd ed. Upper Saddle River, NJ: Prentice Hall, 1999.

YOGO, M. A consumption-based explanation of expected stock returns The Journal of Finance, v. 61, n. 2, p. 539-580, 2006.

VASICEK, O. A. An equilibrium characterization of the term structure Journal of Financial Economics, v. 5, n. 2, p. 177-188, nov. 1977.

VIEIRA NETO, C. A. Modelagem da estrutura a termo da taxa de juros e avaliação de contratos derivativos. São Paulo, 1999. 173 p. Tese (Doutorado em Economia) - FEA-USP.

Artigo convidado. Aprovado em 12.02.2007. 